Psicologia Escolar

e Educacional
ARTIGO

DOI: http://dx.doi.org/10.1590/2175-35392020216354

Elocid - e216354

\title{
MEMÓRIA MEDIADA: PESQUISA EXPLORATÓRIA SOBRE POSSIBILIDADES DE DESENVOLVIMENTO EM CRIANÇAS PRÉ-ESCOLARES
}

\author{
Maria Silvia Pinto de Moura Librandi da Rocha ${ }^{1}(\mathbb{D})$; Marina Pereira Leite ${ }^{1} \mathbb{D}$
}

\begin{abstract}
RESUMO
No presente artigo apresentam-se resultados de pesquisa exploratória visando identificar modos pelos quais crianças pré-escolares podem aprender a utilizar elementos semióticos no aprimoramento de sua memória mediada. O método utilizado foi um jogo de cartas, planejado especialmente para a pesquisa e realizado com 6 grupos de 3 crianças (18 participantes) da faixa etária entre 5 e 6 anos, pertencentes a uma turma de Educação Infantil de uma escola municipal. Os resultados permitiram refletir sobre a apropriação de estratégias de mediação da memória no desenvolvimento humano. Esses resultados são contrastados com as etapas de constituição da memória mediada apresentadas por L. S. Vigotski e colaboradores, destacando-se a importância da mediação do pesquisador e dos pares e seus efeitos sobre o deslocamento entre os níveis de memória. Espera-se que o estudo permita o avanço de pesquisas sobre o tema e contribua para fundamentar práticas pedagógicas potentes para o desenvolvimento das funções psíquicas superiores.
\end{abstract}

Palavras-chave: Memória; Psicologia histórico-cultural; crianças em idade pré-escolar.

\section{Mediated memory: exploratory research on development possibilities in preschool children}

\begin{abstract}
This article presents results of exploratory research aimed at identifying ways in which pre-school children can learn to use semiotic elements to improve their mediated memory. The method used was a card game, planned especially for the research and carried out with 6 groups of 3 children (18 participants) aged between 5 and 6 years old, belonging to a kindergarten class at a municipal school. The results allowed us to reflect on the appropriation of memory mediation strategies in human development. These results are contrasted with the stages of constitution of mediated memory presented by L. S. Vigotski and collaborators, highlighting the importance of the mediation of the researcher and peers and their effects in the displacement between the levels of memory. It is expected that the study will allow the advancement of research on the topic and contribute to support powerful pedagogical practices for the development of higher psychic functions.
\end{abstract}

Keywords: Memory; Historical-cultural Psychology; preschool age children.

\section{Memoria mediada: investigación exploratoria sobre posibilidades de desarrollo en niños preescolares}

\section{RESUMEN}

Se presentan resultados de investigación exploratoria con objetivo de identificar modos por los cuales niños preescolares pueden aprender a utilizar elementos semióticos en el mejoramiento de su memoria mediada. El método utilizado fue un juego de barajas, planeado especialmente para la investigación y realizado con 6 grupos de 3 niños (18 participantes) de la franja de edad entre 5 y 6 años, pertenecientes a un grupo de Educación Infantil de una escuela municipal. Los resultados permitieron pensar sobre a apropiación de estrategias de mediación de la memoria en el desarrollo humano. Estos resultados son contrastados con las etapas de constitución de la memoria mediada presentadas por L. S. Vygotsky y colaboradores, destacándose la importancia de la mediación del investigador y de los pares y sus efectos sobre el desplazamiento entre los niveles de memoria. Se espera que el estudio permita el avance de investigaciones sobre el tema y colabore a fundamentar prácticas pedagógicas potentes al desarrollo de las funciones psíquicas superiores.

Palabras clave: Memoria; Psicología Histórico-cultural; niños en edad preescolar.

1 Pontifícia Universidade Católica de Campinas - Campinas - SP - Brasil; silrocha@uol.com.br; marinapeleite@gmail.com 


\section{INTRODUÇÃO}

A memória é uma função psicológica vital para os seres humanos, para sua inserção no mundo social, cultural e na história. No entorno de todos os sujeitos, uma miríade de artefatos e instrumentos semióticos está disponibilizada para que aprendam e recordem quem são e o que devem fazer. Estamos cercados por marcas culturais que nos constituem e afetam nossa memória: os monumentos, os museus, as variadas formas culturais de registrar o tempo, os cemitérios, as fotografias, a literatura... Nas escolas, as agendas, os cartazes, os cadernos de comunicação escola-família... Ao longo do processo de desenvolvimento, porém, será necessário que cada sujeito, a partir de suas relações sociais, aproprie-se desses instrumentos e, além disso, aproprie-se das suas múltiplas formas de produção e uso que lhe permitam regular sua própria memória.

A teoria Histórico-Cultural, ao tratar da constituição e do desenvolvimento da memória, distingue a natural da memória cultural ou mediada. Para teorizar sobre esses dois conceitos, L. S. Vigotski, fundador desse modelo teórico, dialoga, criticamente, com outras abordagens da Psicologia e constrói uma maneira original de investigar essa função. Rejeitando os princípios e métodos clássicos da ciência psicológica de sua época, esse autor e seus colaboradores buscam compreender não só a estrutura e a ampliação quantitativa da capacidade de lembrar, mas, principalmente, a origem de transformações qualitativas da memória, na história da humanidade e na vida de cada sujeito.

Para o estudo da memória, Vigotski realizou análises microgenéticas ${ }^{1}$ a partir de material empírico produzido através do chamado "método da dupla estimulação", qualificado pelo próprio autor como "método fundamental que se utiliza, habitualmente, ao estudar a conduta cultural das crianças" (Vygotski, 1995, p. 161). O formato básico desse método consistia em colocar sujeitos em uma situação estruturada na qual havia uma tarefa a ser executada e os participantes recebiam orientações no sentido da construção de meios para chegar à sua resolução. Uma situação tipicamente construída para estudar a constituição da memória mediada era a de solicitar às crianças que pressionassem teclas específicas respondendo a determinados estímulos (por exemplo, pressionar a tecla vermelha quando lhe fosse apresentada a figura de um cavalo, a tecla verde no caso da apresentação da figura de um pão, e assim por diante). No desenrolar dos experimentos, eram oferecidas fichas com figuras (chamadas por Vigotski de

\footnotetext{
${ }^{1}$ Conforme Góes, "dentre as diretrizes metodológicas que [Vigotski] explorou, estava incluída a análise minuciosa de um processo, de modo a configurar sua gênese social e as transformações do curso de eventos. Essa forma de pensar a investigação foi denominada por seus seguidores como “análise microgenética". (Góes, 2000, p. 11).
}

vários modos: estímulos-meio, cartões-meio, estímulos-signos) e sugeria-se aos participantes que as utilizassem como recurso auxiliar para lembrar qual tecla deveriam pressionar. Analisavam-se, então, os usos que as crianças faziam (ou não) dos cartões e os efeitos desses na performance geral e no aprimoramento (ou não) da memória. Várias versões desses experimentos foram utilizadas nos estudos sobre a memória, a depender de objetivos específicos que se almejava atingir. Um dos recursos utilizados por Vigotski e seus colaboradores para análises do desempenho das crianças consistia em quantificar os sucessos na tarefa e, a partir disso, comparar resultados, considerando idades e níveis de escolarização, relacionar esses resultados às maneiras como os cartões haviam sido incorporados (ou não) no desenrolar do experimento e traçar as linhas de desenvolvimento da "memória natural" e da "memória cultural", comparando-as também.

A intenção de Vigotski, portanto, é ir na contramão da simplificação do processo, argumentando que a Psicologia associacionista era insuficiente para esclarecê$-\mathrm{lo}^{2}$. Com esses experimentos foi possível perceber como as crianças tornavam-se, gradualmente, capazes de reorganizar o funcionamento de sua memória com apoio de recursos semióticos. Nesses estudos apresentam-se, portanto, fundamentos para explicar o desenvolvimento cultural da memória mediada e a função do signo na elaboração de novas estruturas mnemônicas. Um desses fundamentos diz respeito a certas regularidades identificadas nas sucessivas reorganizações quanto ao uso de recursos externos e suas relações com a capacidade de lembrar. Essas regularidades foram sistematizadas em etapas e apresentadas por Vygotski (1995) da seguinte forma:

1. Memorização mecânica, referente à capacidade básica de memorizar das crianças desde muito pequenas; pode ser identificada na repetição de ações motoras, na aprendizagem e retenção do nome de um grande número de objetos, de animais etc.;

2. Psicologia ingênua: nesta etapa as crianças já fazem uso de recursos mediacionais, mas ainda não compreendem, plenamente, sua função; por exemplo, tendo tido êxito ao escolher a ficha com a imagem de uma faca para se lembrar da palavra pão, escolhem-na novamente, para se lembrar da palavra sofá; começam a empregar signos, sem entender, de modo mais consistente, como atuam;

\footnotetext{
${ }^{2}$ Para a Psicologia Associacionista todas as funções psíquicas deveriam ser investigadas buscando-se o processo de associação entre estímulo - resposta (E - R). Uma das primeiras contribuições da Psicologia Histórico-cultural foi mostrar a importância de se inserir um elemento mediador (o signo) nessa relação, para se compreender o psiquismo humano; em vários trabalhos Vigotski esquematiza essa tese, com uma imagem triangular, dispondo nos vértices do triângulo os elementos $\mathrm{E}-\mathrm{S}-\mathrm{R}$.
} 
3. Memorização mnemotécnica externa: as crianças em idade escolar começam a fazer uso sistemático de recursos mediacionais, desde que haja uma ligação simples entre eles e as palavras a serem lembradas; gradualmente, tornam-se capazes de criar relações novas e menos evidentes entre os elementos, para ajudá-las a lembrarem-se;

4 Internalização e memória lógica: o manejo externo de signos externos é substituído pela atividade mental interna; é o ponto máximo do uso de meios culturais e o desenvolvimento da memória mediada.

Embora os estudos sobre a memória mediada ocupem centralidade nos trabalhos de Vygotski (1995), A. R. Luria (1979) e A. N. Leontiev(1978), não se encontram na literatura científica contemporânea repercussões expressivas. A pesquisa bibliográfica ${ }^{3}$ realizada buscando estudos sobre a memória revelou a prevalência de trabalhos não fundamentados nesse modelo teórico; nesses estudos os procedimentos são estritamente controlados, com uso de testes e escalas, desenvolvidos a partir de hipóteses bem definidas; estudos sobre a memória mediada feitos a partir dos aportes da teoria Histórico-cultural têm sido pouco frequentes no contexto científico contemporâneo. No conjunto de pesquisas analisadas, considerando-se as que se referenciavam nesse modelo teórico, a memória foi mencionada de forma periférica e apenas em uma exceção (Solovieva \& Quintanar, 2013), os pesquisadores tiveram participação como desencadeadores de novos modos de funcionamento psicológico. Os conceitos de memória operacional ou de trabalho, memória de curta e de longa duração, memória de reconhecimento e memória sensorial, têm sido os mais frequentemente utilizados e, prioritariamente, relacionados com as chamadas neurociências ${ }^{4}$. Destacam-se abordagens que elegem aspectos quantitativos no estudo da memória, analisados em dois eixos: quantidade de elementos registrados e rememorados e quantidade de tempo no seu funcionamento. Além disso, de acordo com Silva,

\footnotetext{
${ }^{3}$ A pesquisa bibliográfica foi feita na base de dados ScopusElsevier buscando no título, palavras-chave ou resumo, o descritor "memory". Em seguida, foram selecionados apenas artigos, escritos em inglês, espanhol ou português, publicados no período de 2011-2017 e utilizando filtros para as sub-áreas "Artes e Humanidades", "Ciências Sociais" e "Psicologia". Encontramos 11.670 artigos. Selecionando os artigos que referenciavam pelo menos um dos três autores principais na da teoria Histórico-cultural (L.S. Vygotsky, A. R. Luria e A. N. Leontiev) restaram 171 trabalhos. Desses, analisamos os que realizaram pesquisa empírica com crianças dentro da faixa etária de 3 a 12 anos, restando 52 artigos. (Lisboa; Rocha, 2016).

${ }^{4}$ Os trabalhos de Jaeger, Galera, Stein e Lopes (2016) e de Mourão Júnior e Faria (2015) são exemplares neste campo, pois são propostos como revisões teóricas sobre o que os autores consideram os tópicos e conceitos mais importantes a respeito do estudo da memória.
}

Sirgado e Tavira (2012), ressalta-se que

O problema maior dessa forma tão difundida de conceber a memória humana (algo que vale também para as outras funções psicológicas) é ver nela o resultado do mero desenvolvimento orgânico do indivíduo em interação com o meio, ignorando as condições culturais e históricas da constituição do humano, em que a cultura e a realidade social desempenham papel fundamental. (p. 267).

Considera-se, portanto, relevante retornar aos experimentos realizados por Vigotski e, inspirando-se neles, perscrutar a possibilidade de aprimorar os conhecimentos sobre o desenvolvimento da memória mediada.

\section{MÉTODO}

Trata-se de pesquisa exploratória realizada junto a uma turma de Educação Infantil de uma unidade da rede municipal da cidade de Campinas/São Paulo, com objetivo de investigar o uso de sistemas externos de representação e as contribuições de práticas pedagógicas na constituição social da memória. Em colaboração com a professora da turma, foram investigadas possibilidades de construção de novos sistemas e/ou de transformar alguns que já se encontravam inseridos no cotidiano escolar. Dessa forma, cartazes com os nomes dos alunos, com lista de músicas, calendário e um jogo de cartas foram construídos e usados com as crianças. No presente artigo, apresentam-se os resultados desse último procedimento.

\section{Participantes}

A pesquisa foi realizada com 18 crianças (11 meninas e 9 meninos), de idade entre 5 e 6 anos. Antes de seu início, foi submetida ao Comitê de Ética de Pesquisa e aprovada sob o protocolo número 19092613.6.0000.5481.

\section{Local}

O procedimento foi realizado na sala regular da turma de Educação Infantil de uma escola municipal.

\section{Material}

Foi utilizado um Jogo da Memória, construído especialmente para o desenvolvimento da investigação, composto por 15 cartas com figuras que representavam as palavras que deveriam ser lembradas pelas crianças e por $\mathbf{2 5}$ minifichas com figuras que podiam ser usadas pelos participantes como mediadores para se lembrarem das palavras. Dessas minifichas, 15 tinham imagens com relação mais explícita com as palavras a serem lembradas e 10 tinham imagens não explicitamente relacionadas às palavras. No Quadro 1 apresenta-se a lista das figuras escolhidas, separadas por categorias definidas pelas pesquisadoras como relacionadas ou não às cartas. Na Figura 1 são apresentados exemplos de carta e de minifichas que compuseram o jogo. 


\begin{tabular}{|c|c|c|}
\hline CARTAS & $\begin{array}{c}\text { FICHAS } \\
\text { com figuras relacionadas }\end{array}$ & $\begin{array}{c}\text { FICHAS } \\
\text { com figuras não } \\
\text { relacionadas }\end{array}$ \\
\hline macaco & banana & \\
\hline bola & gol & \\
\hline faca & garfo & \\
\hline fogão & panela & \\
\hline copo & jarra & \\
\hline caderno & lápis & \\
\hline coelho & cenoura & \\
\hline sapato & meia & \\
\hline cachorro & osso & \\
\hline mesa & cadeira & \\
\hline palhaço & circo & \\
\hline carro & pneu & \\
\hline ovo & galinha & \\
\hline vaso & flor & \\
\hline \multirow[t]{11}{*}{ pasta de dente } & escova de dente & \\
\hline & & rato \\
\hline & & ventilador \\
\hline & & boneca \\
\hline & & pipa \\
\hline & & árvore \\
\hline & & peixe \\
\hline & & bicicleta \\
\hline & & fada \\
\hline & & televisão \\
\hline & & maçã \\
\hline
\end{tabular}

Quadro 1. Lista das imagens que compuseram o jogo de cartas.

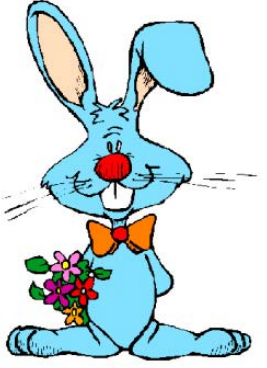

Figura 1. Exemplos de imagens das cartas e minifichas

\section{Procedimento}

A aplicação do jogo foi feita no período após a roda inicial do dia e antes do recreio, com grupos compostos por três crianças por vez; cada partida tinha três rodadas. No total, trabalhou-se com 6 grupos, totalizando 18 rodadas.

No início de cada partida, a pesquisadora dizia: “Este é um jogo da memória diferente. Cada um de vocês terá que se lembrar de 5 palavras na sua vez de jogar". A pesquisadora mostrava as 15 cartas para as crianças e explorava com elas os nomes das figuras. Em seguida, recolhia as cartas e colocava todas as minifichas sobre a mesa, com as figuras visíveis. Eram, então, dadas as seguintes instruções: "Estas fichas têm outros desenhos que vocês podem usar, que podem ajudar vocês a se lembrarem das palavras. Cada palavra que vocês acertarem, vocês ganham uma carta". A pesquisadora separava 5 cartas e falava os nomes das figuras para a primeira criança que iria jogar e relembrava que poderia usar as minifichas sobre a mesa. A pesquisadora repetia os nomes das figuras, pausadamente, e aguardava a escolha das minifichas. Solicitava, então, que a criança repetisse as 5 palavras. A cada palavra acertada, a criança ganhava a carta correspondente. Em seguida, a pesquisadora repetia o procedimento para a segunda e terceira crianças participantes. Ao final da primeira rodada, contavam-se as cartas que cada jogador tinha 
e registrava-se numa folha. Seguia-se nova rodada.

No decorrer das partidas, em função da facilidade com que as crianças compreenderam o jogo, foram feitas algumas mudanças. Primeiramente, as crianças passaram a ouvir os nomes das cinco cartas, escolher as minifichas e aguardar que todos os participantes fizessem o mesmo. Somente depois que todos haviam escolhido as minifichas, iniciava-se a segunda etapa, na qual elas falavam quais eram as cartas. Essa alteração no procedimento visou tornar mais difícil a recordação e mais necessário o uso das minifichas.

Em função dessas mudanças, a variedade de minifichas diminuiu para os participantes que não fossem os primeiros a retirá-las, podendo afetar suas escolhas. Por exemplo, uma criança não poderia escolher a minificha da banana, se já tivesse sido escolhida pelos jogadores anteriores. $O$ acervo de minifichas foi triplicado, repetindo-se cada imagem 3 vezes. Essas novas regras não provocaram mudanças significativas nas pontuações finais das partidas; a maior parte das crianças prosseguiu evidenciando ter dominado a estratégia de mediar sua memória com as minifichas.

\section{RESULTADOS}

Desde a primeira rodada as crianças tiveram muita facilidade em memorizar as cartas distribuídas; isso é evidenciado pelo elevado número de vezes em que atingiram a pontuação máxima ou erraram apenas uma carta. As observações durante as idas a campo e a análise dos vídeos possibilitam destacar o alto envolvimento com o jogo: quando a atividade era apresentada, exploravam com interesse o material, buscavam compreender as regras, conhecer as peças, conversar sobre as cartas e minifichas. Em algumas situações identificamos competitividade entre crianças; porém isso se deu como uma brincadeira esporádica, como a transcrita no episódio 01.

\section{Episódio 01}

Marcy se manifesta quando Daniela acerta a terceira figura.

Marcy: Aiiiiiiii! Daniela!!!!!!!

Daniela e Mariana sorriem.

Daniela [responde para a pesquisadora]: Vaso.

A pesquisadora entrega a carta correspondente, mostrando que Daniela acertou novamente. Marcy fala antes de Daniela realizar sua última jogada.

Marcy: Drooooooga!! Erra, erra, erra por favor! Erra!

Outra conduta registrada de modo pontual e mais frequente nos primeiros contatos com o material foram os comentários das crianças sobre as imagens:

\section{Episódio 02}

Marcy: Ai que bonitinhaaaa! Bonitinhaaaa!!!
Pesq.: Qual que é?

Marcy mostra a carta da boneca.

Pesq.: Ah, da boneca. Essas cartinhas ajudam a gente a lembrar das cartonas.

Marcy: Você me dá essa?

A seguir apresenta-se o trabalho analítico com foco, inicialmente, no grupo em que foram identificadas as maiores mudanças em termos de resultados. Este grupo foi composto por Marcy, Daniela e Mariana que fizeram, respectivamente as seguintes pontuações, a cada partida: Mariana $(0,1,4)$, Marcy $(1,1,5)$ e Daniela $(4,3,5)$.

\section{Episódio 03}

Pesq.: [...] tem cinco cartas para a Mariana, cinco cartas para a Marcy e cinco cartas para a Daniela. Eu vou ler essas cartas, vou falar quais são. Vou começar com a Mariana. Tá bom? Pode ser? Você vai olhar aqui (aponta as minifichas) e ver quais cartas te ajudam a lembrar as que eu vou falando.

Marcy: Eu não lembro dessas (aponta para as cartas grandes).

Pesq.: Mas eu ainda vou falar... Essas cartinhas ajudam a gente a pensar.

Marcy: Por isso você trouxe essas?

Pesq.: Por isso eu trouxe essas. Pra ajudar a gente a lembrar.

Marcy: Tomara que essas duas não escolham a que eu quero.

Marcy, Mariana e Daniela riem.

Pesq.: Então vai. (olha para a Mariana). Fogão.

Mariana aponta a imagem da boneca e olha para a pesquisadora

Pesq.: Escolhe as que você acha que vão te ajudar a lembrar do fogão.

Mariana pega a minificha com a imagem da boneca; Daniela olha para Marcy, que, por sua vez, observava a carta que Mariana escolhia.

Pesq.: Mariana, ó! Eu vou falar e depois você tem que lembrar das cartas que eu falei.

Mariana: Mas eu não lembro.

Pesq.: Essas cartas (aponta as minifichas) estão aqui pra te ajudar a lembrar. Ó, que é que tem aqui que te lembra de fogão?

Mariana continua a olhar para a pesquisadora.

Pesq.: Olha estas cartas (minifichas). Tem coisa aqui que ajuda a lembrar de fogão?

Marcy: Coisa parecida com fogão.

Mariana observa as cartas. Marcy e Daniela se entreolham.

Pesq.: Pode procurar... Pode pegar as que te ajudam 
a lembrar de fogão.

Mariana: As que parecem fogão?

Pesq.: As que lembram.

Marcy: Pega coisa de cozinha então, pra lembrar, né?

Pesq.: O que te lembra fogão? Coisa de cozinha lembra fogão?

Marcy: Lembra.

Mariana coloca o dedo próximo à figura de panela, e, lentamente, puxa a minificha para perto de si e a entrega para a pesquisadora. Parece estar bastante em dúvida sobre a escolha.

Esse fragmento é a primeira experiência das três meninas com o jogo e elas lidam com o material de modo que parece ir se aproximando do que Vigotski nomeou como "psicologia ingênua", o segundo nível proposto pelo autor sobre o desenvolvimento da memória mediada. Inicialmente, tanto Marcy quanto Mariana demonstram ter consciência sobre os limites de sua memória, verbalizando "Eu não lembro dessas" e "Mas eu não lembro". O poder das minifichas não está claro. A primeira escolha de Mariana, pegando a boneca após a pesquisadora ter dito a palavra fogão, muito provavelmente está circunstanciada pelas manifestações anteriores da colega Marcy, salientando aspectos estéticos da figura, ao dizer: "Ai que bonitinhaaaa! Bonitinhaaaa!!!" e mostrar que gostaria de escoIher essa imagem. A possibilidade de uso de recursos mediacionais, como a panela para lembrar fogão vai sendo construída gradativamente e como função das interações entre a criança que joga com suas colegas e a pesquisadora. O que diz cada uma das participantes vai fazendo diferença no modo de todas interpretarem a situação e irem refinando sua compreensão sobre o jogo. Mariana escolhe a panela, sem parecer compreender totalmente sua função, sem saber como, de modo mais preciso, poderá prosseguir utilizando tais minifichas, depois dessa escolha. As minifichas que elege nessa primeira rodada não lhe permitem êxito na tarefa de lembrar as cartas que a pesquisadora tem em mãos, embora, do ponto de vista lógico, Mariana tenha feito boas escolhas, como se pode verificar no Quadro 02.

Na sequência de rodadas, as crianças dão pistas de compreensão do jogo, reproduzindo as perguntas feitas pela pesquisadora. As primeiras rodadas em que Marcy (episódio 04) e Daniela (episódio 05) devem ouvir as palavras, escolher as minifichas e relembrar as imagens das cartas, ocorreram como transcrito a seguir.

\section{Episódio 04}

Pesq.: Carro.

Marcy fica olhando as imagens.

Mariana: $O$ que parece com o carro?

Marcy escolhe a minificha da televisão.
Pesq.: Ovo

Mariana: É. O que que te lembra ovo?

Em seguida, Mariana observa a figura da televisão na mão de Marcy.

Mariana: Tv te lembra carro?!?

Marcy pega a figura de um garfo.

\section{Episódio 05}

Pesq.: O que te lembra coelho?

Mariana: Cachorro não. Não é cachorro não. Ela pode escolher também uma cenoura. Cenoura lembra coelho.

\section{Marcy: Cenoura lembra coelho.}

Daniela pega a imagem de um rato, coloca junto com as outras minifichas que havia separado. Olha para a pesquisadora.

Marcy: Rato?!?

Pesq.: Escolheu? (Pergunta para Daniela).

Daniela afirma que sim com a cabeça, olhando para a colega. Mariana ri e comenta a escolha, com crítica.

Mariana: Um raaaato! (ri) É a cenoura!

Pesq.: Vai Daniela. O que te lembra vaso?

Daniela corre o olhar pelas imagens e escolhe um pneu.

Embora a pesquisadora orientasse as crianças para que não interferissem nas jogadas alheias, o controle sobre isso nunca foi pleno. Na maior parte das vezes, as crianças intervinham para ajudar as colegas: se Marcy, no episódio 01, fica torcendo para que Daniela erre, no episódio 05 auxilia-a, sugerindo o par coelho - cenoura. Também é importante destacar que, ao longo da rodada, Mariana vai refinando seu modo de pensar sobre o jogo, refinamento indiciado/sustentado pela substituição do verbo parecer (do enunciado "O que parece com carro") pelo verbo lembrar (dos enunciados "O que que te lembra ovo?", "Tv te lembra carro?!?" e "Cenoura lembra coelho"). As escolhas inusitadas dos pares carro - tv, coelho-rato são motivo de espanto e de ironia. Mas o mesmo não ocorre quanto ao par vaso-pneu.

No decorrer das partidas, várias crianças elegeram a figura do pneu para se lembrarem da carta com um vaso, conseguindo mais tarde realizar a associação corretamente: ao olharem para a imagem do pneu, diziam vaso. Uma possível explicação para isso é que na área de parque e no jardim da escola havia vários vasos feitos com pneus. Existia, portanto, a possibilidade de que as crianças relacionassem a imagem do pneu à do vaso, apoiando-se nessa experiência. Constata-se, assim, que as crianças estabelecem relações próprias, ativamente, partindo e apoiadas nas experiências que têm em seus contextos sócio-culturais específicos; realizam novas associações entre as cartas e as minifichas, além das 
esperadas e/ou mais óbvias.

Se no caso do par vaso - pneu podemos identificar uma base para a relação inusitada estabelecida, em outros momentos isto não ocorre, como apontamos a seguir. Nos pares formados há prevalência de relações seguindo a lógica mais estabilizada, culturalmente. Das 45 escolhas, em 28 vezes, as crianças fazem isso, excluindo-se desse total os pareamentos vaso - pneu. Elegem, porém, algumas minifichas por razões que nos escapam, formando pares tais como: faca - televisão, bola - lápis, sapato - circo. É importante, porém, notar que em alguns casos essa relação funciona e as crianças conseguem nomear a figura da carta corretamente. Este tipo de desempenho pode ser notado nas escolhas e acertos de Mariana, na terceira rodada, apresentados no Quadro 2. Teria sido muito interessante explorar, após o jogo, as razões dos pareamentos inusitados, das possibilidades criativas do uso das imagens. Porém, como isso não foi feito, não podemos avançar na compreensão dessas escolhas.

Em função dos nossos objetivos e dos fundamentos teóricos assumidos, a quantidade de acertos importa, mas, sobretudo é necessário destacar as mudanças qualitativas que vão se operando na sequência das partidas. Embora em alguns momentos não tenha sido possível identificar, com precisão, para qual minificha as crianças olhavam antes de se lembrarem das palavras faladas pela pesquisadora, o fato é que há um movimento crescente de levá-las em consideração. As ações de olhar para a pesquisadora, para as colegas ou para vários lugares, vão sendo, gradualmente, substituídas por uma clara orientação do olhar para as minifichas,

\begin{tabular}{|c|c|c|}
\hline CARTAS LIDAS & MINIFICHAS ESCOLHIDAS & CARTAS ACERTADAS \\
\hline \multicolumn{3}{|c|}{ PRIMEIRA RODADA } \\
\hline Fogão & Panela & \\
\hline Sapato & Meia & \\
\hline Cachorro & Galinha & \\
\hline Pasta de dente & Escova de dente & \\
\hline Palhaço & Circo & \\
\hline \multicolumn{3}{|c|}{ SEGUNDA RODADA } \\
\hline Macaco & Banana & \\
\hline Vaso & Rosa & \\
\hline Palhaço & Circo & $\checkmark$ \\
\hline Bola & Trave de gol & \\
\hline Ovo & Garfo & \\
\hline \multicolumn{3}{|c|}{ TERCEIRA RODADA } \\
\hline Faca & Televisão & \\
\hline Bola & Lápis & $\checkmark$ \\
\hline Sapato & Circo & $\checkmark$ \\
\hline Fogão & Garfo & $\checkmark$ \\
\hline Caderno & Lápis & $\checkmark$ \\
\hline
\end{tabular}

Quadro 2. Relações entre cartas e minifichas feitas por Mariana e acertos 
bem como pelo procedimento de ir separando-as, na medida em que eram utilizadas como mediadoras das palavras. Registros como os da primeira participação de Mariana, em que vai nomeando as palavras "cenoura, boneca, uma árvore, galinha...", sem acertar nenhuma e, principalmente, olhando para a pesquisadora, vão desaparecendo.

Em contrapartida, intervenções como as de Marcy para Mariana, dizendo "Pensa aí, na sua cabeça, vai. Pode olhar nessas cartinhas?", sugerindo e, ao mesmo tempo pedindo confirmação para a pesquisadora ou "Olha aqui (indicando as minifichas que a amiga escoIheu). Põe tudo assim na mesa, então, pra você ver", vão se tornando mais frequentes e se consolidando. São pequenas participações e gestos, mas dão pistas de que Mariana se apropriou de aspectos importantes da situação, embora em algumas circunstâncias mais formais do que efetivos, porque organizar as minifichas no campo de visão é importante, mas não é suficiente para as ações efetivas da memória.

Trata-se, portanto, de um ponto crucial, pois denota mudanças qualitativas nas operações cognitivas em jogo. É verdade, porém, que, em alguns momentos, esta ação não redunda em acertos, seja porque a minificha escolhida não remete com força à palavra a ser lembrada, seja porque a imagem da minificha prevalece sobre a relação estabelecida com a palavra que deve ser recordada. Em sete vezes registramos o ato de nomear a figura da minificha e não a da carta, a qual essa deveria remeter. Algumas considerações sobre o papel da mediação da pesquisadora são pertinentes.

A relação das crianças com as imagens, no geral, seguiu essa dinâmica: escolhiam uma minificha para cada palavra falada pela pesquisadora, organizavam-se a partir de observações dos jogos de outros colegas, apropriando-se de suas estratégias, como organizar as minifichas escolhidas para observá-las melhor e relembrar as palavras, em suas próximas jogadas. Foi possível notar que, via de regra, a apropriação da estratégia de mediação da memória se aperfeiçoava e aumentavam os acertos nas últimas rodadas, tal como se exemplifica nos episódios 06 e 07.

\section{Episódio 06}

Pesq.: Quer me contar? Qual que você acha que tá aqui?

Eloísa apoia-se sobre a mesa e fica observando os colegas conversarem.

Pesq.: Quais que você acha Eloísa?

Eloísa: Não sei.

Eloísa olha para as minifichas que separou e para a pesquisadora.

Pesq.: Olha aínessas cartinhas pra elas te ajudarem a lembrar. De quais você lembra quando você olha aí?
Eloísa olha suas minifichas, em silêncio. Distribui sobre a mesa, separando-as de maneira que todas fiquem bem visíveis; observa-as. A pesquisadora faz uma pausa para que Eloísa analise o conjunto de fichas e depois retoma.

Pesq.: Que que esse pneu te lembra?

Eloísa observa as imagens.

Eloísa: $O$ carro.

Pesq.: O carro! Acertou!

\section{Episódio 07}

Pesq.: Agora o Carlos. Me conta o que você tem aí?

Carlos: Cadeira (coloca a minificha da cadeira na mesa).

Pesq.: Cadeira te lembra o que?

Carlos: A mesa.

Pesq.: A mesa.

Carlos: Panela (coloca a imagem de uma panela na mesa).

Pesq.: O que a panela lembra?

Carlos: Fogão.

Pesq.: Fogão.

Carlos: Flor (coloca a imagem de uma flor na mesa).

Pesq.: Que a flor lembra?

Carlos: Vaso.

Pesq.: $O$ vaso.

Carlos: Escova (coloca a imagem de uma escova).

Pesq.: O que a escova lembra?

Carlos: Pasta.

Pesq.: Pasta.

No decorrer das jogadas, as proposições da pesquisadora vão fazendo diferença. Nas respostas de Carlos, inicialmente ocorre predominância de nomeação direta a partir da visão da minificha; entretanto, a utilização - pela pesquisadora - do verbo lembrar permite uma reformulação da estratégia de raciocínio e ele e Eloísa passam a responder corretamente, nomeando as figuras que devem ser lembradas. Salientamos aqui a importância de que a participação dos pesquisadores seja também objeto de análises. De maneira distinta de desenhos experimentais clássicos, em que os pesquisadores devem ter papel neutro e homogêneo, inspirando-nos em Vigotski e seus colaboradores, assumimos a pertinência de variações nas proposições do investigador com objetivo de criar as melhores condições possíveis de trabalho psicológico para os participantes e, preferencialmente, que contribuam para ocorrência de transformações. A diretriz metodológica geral de analisar processos e não produtos sustenta essa dinâmica em que os investigadores são parte integrante e constitutiva das respostas que cada criança dá. Advertimos, porém, 
que esta é uma tarefa complexa e que nem sempre foi feita de modo aprofundado nos trabalhos inaugurais de estudo da memória, ao menos levando em consideração os textos de Vigotski de que dispomos ${ }^{5}$.

A partir das análises dos modos e processos de constituição da memória mediada registrados no desenrolar da pesquisa, e contrastando-os com os níveis de memória mediada propostos por Vigotski, é importante destacar que nas estratégias usadas pelas crianças prevaleceram as de nível três, denominada como Memorização Mnemotécnica Externa. Embora o próprio autor sugira que não há estabilidade plena em cada nível, ocorrendo, como demonstram os resultados de nossa pesquisa, variações no uso de recursos mediadores pelas crianças, ressaltamos que nas pesquisas originais que tomamos como referência, extraídas dos volumes da coleção Obras Escogidas (especialmente Vygotski, 1995) e de textos escritos em co-autoria com seus colaboradores (destacando-se Vygotsky \& Luria, 1993/1996), as operações do tipo memorização mnemotécnica externa são registradas nas pesquisas com crianças a partir de 7 anos, período do início da vida escolar, no contexto russo da época. Assim, é de se notar que os participantes de nosso estudo conseguiram realizar operações de uso de apoios externos para a memória, na maior parte das vezes, de modo muito eficiente, em média dois anos antes do que os estudos de Vigotski apontaram.

Sem dúvida, é relevante considerar que algumas mediações da pesquisadora e dos colegas colaboraram para operações cognitivas mais apuradas, afetando, assim, o desempenho no jogo. Entretanto, essa ressalva, ao contrário de diminuir a importância dos nossos resultados, intensificam-nos, pois mostram a potência da intervenção social na constituição e desenvolvimento das funções psicológicas superiores.

\section{DISCUSSÃO}

Para a teoria Histórico-Cultural, a compreensão do funcionamento da mente humana em níveis superiores, propriamente humanos, deve considerar a interpenetração das funções psíquicas, tendo as experiências sociais como estatuto de sustentação fundamental para essas mudanças. Neste trabalho, retomamos o desenho experimental das pesquisas realizadas por seus fundadores; mas fizemos nele modificações que queremos aqui realçar: a proposição de uso de signos num jogo

\footnotetext{
${ }^{5}$ Conforme abordamos em outro texto, em muitos momentos da obra de Vigotski as descrições dos experimentos são feitas com poucas minúcias, com pouco detalhamento; são lacunares em muitos aspectos; não há esclarecimentos, por exemplo, quanto a se foram feitos apenas individualmente ou também em grupos, quanto à existência de situações em que uma mesma criança participava de mais de uma sessão, se havia algum tipo de análise longitudinal, entre outros aspectos. (Toesca; Rocha, 2017).
}

de cartas simples e na própria sala de aula. Certamente existem outras múltiplas possibilidades de atividades e práticas pedagógicas que podem ser inseridas no cotidiano da educação infantil e que podem contribuir para que a capacidade de mediação da memória se enriqueça. Pela linguagem, própria, dos colegas e da pesquisadora, a criança produz significações sobre 0 mundo, tornando-se cada vez mais consciente dele e de si própria e desenvolvendo, de forma mais abstrata e reflexiva, suas funções psicológicas superiores.

Esperamos também que o trabalho aqui apresentado possa inspirar novas pesquisas desse tipo, que poderão contribuir para evidenciar que o papel da escola é ainda mais amplo do que o já apontado pelos autores com quem dialogamos e a possibilidade de enriquecimento do trabalho pedagógico parece-nos um caminho profícuo para aprimorar as capacidades dos que dela participam, assim como para aprimorar a teoria que o fundamenta. Os resultados indicam que um trabalho específico e explícito com as crianças sobre sua memória e modos de regulá-la pode levar a um desenvolvimento importante de tomada de consciência sobre as funções psicológicas.

\section{REFERÊNCIAS}

Góes, M. C. R. (2000). A Abordagem Microgenética na Matriz Histórico-cultural: uma perspectiva para o estudo da constituição da subjetividade. Relações de Ensino: análises na perspectiva Histórico-cultural. Cadernos Cedes, 20(50), 9-25. https://doi.org/10.1590/S0101-32622000000100002

Jaeger, A.; Galera, C. A.; Stein, L. M.; Lopes, E. J. (2016). Human Memory Research: current hypotheses and new perspectives. Estudos de Psicologia, 21(2), 92103. Recuperado de http://www.scielo.br/scielo. php?script=sci_arttext\&pid=S1413-294X2016000200092

Leontiev, A. (1978). O Desenvolvimento do Psiquismo. Lisboa: Livros Horizonte.

Lisboa, C. B.; Rocha, M. S. P. M. L. (2016). A memória mediada: pesquisa bibliográfica. In: XXI Encontro de Iniciação Científica e VI Encontro de Iniciação em Desenvolvimento Tecnológico e Inovação, 2016, Campinas. Anais do XXI Encontro de Iniciação Científica PUC-Campinas. v. 01, pp. 01-05.

Luria, A. R. (1979). Curso de Psicologia Geral. Volume III: Atenção e Memória. Rio de Janeiro: Civilização Brasileira.

Mourão Júnior, C. A.; Faria, N. C. (2015). Memória. Psicologia: Reflexão e Crítica, 28(4), 780-788. Recuperado de http://www.scielo.br/pdf/prc/v28n4/0102-7972prc-28-04-00780.pdf

Silva, D. N. H.; Sirgado, A. P.; Tavira, L. V. (2012) Memória, Narrativa e Identidade Profissional: analisando memoriais docentes. Cadernos Cedes, 32(88), 263-283.

Solovieva, Y.; Quintanar, L. (2013). Evaluación del Desarrollo Simbólico en Niños Preescolares Mexicanos. Cultura y 
Educación, 25(2), 167-182. Recuperado de https://www. tandfonline.com/doi/abs/10.1174/11356401380663127 3 ?journalCode=rcye20

Toesca, D. P.; Rocha, M. S. P. M. L. (2017). A memória mediada e o papel do outro em seu desenvolvimento: os experimentos de L. S. Vigotski em foco. In: XXII Encontro de Iniciação Científica e VII Encontro de Iniciação em Desenvolvimento Tecnológico e Inovação, 2017, Campinas. Anais do XXII
Encontro de Iniciação Científica PUC-Campinas. v. 01, pp. 01-06.

Vygotski, L. S. (1995). Obras Escogidas: Volumes III. Madrid: Visor.

Vygotsky, L. S.; Luria, A. R. (1996). (L. L. Oliveira, trad.). Estudos sobre a História do Comportamento Humano: símios, homem primitivo e criança. São Paulo: Artes Médicas. (Trabalho originalmente publicado em 1993).

Apoio: Agradecemos à FAPESP pelo auxílio financeiro de apoio à pesquisa e ao CNPq pela bolsa PIBIC de Iniciação Científica.

Recebido: 10 de novembro de 2018

Aprovado: 11 de março de 2020 